$$
\text { Special Article }
$$

\title{
PHYSICIAN-ASSISTED DEATH IN PSYCHIATRIC PRACTICE IN THE NETHERLANDS
}

\author{
Johanna H. Groenewoud, M.D., Paul J. van der Maas, M.D., Ph.D., Gerrit van der Wal, M.D., Ph.D., \\ Michiel W. Hengeveld, M.D., Ph.D., Alfons J. Tholen, M.D., Ph.D., Willem J. Schudel, M.D., Ph.D., \\ and Agnes van der Heide, M.D., Ph.D.
}

\begin{abstract}
Background In 1994 the Dutch Supreme Court ruled that in exceptional instances, physician-assisted suicide might be justifiable for patients with unbearable mental suffering but no physical illness. We studied physician-assisted suicide and euthanasia in psychiatric practice in the Netherlands.
\end{abstract}

Methods In 1996, we sent questionnaires to 673 Dutch psychiatrists - about half of all such specialists in the country - and received 552 responses from the 667 who met the study criteria (response rate, 83 percent). We estimated the annual frequencies of requests for physician-assisted suicide by psychiatrists and actual instances of assistance.

Results Of the respondents, 205 (37 percent) had at least once received an explicit, persistent request for physician-assisted suicide and 12 had complied. We estimate there are 320 requests a year in psychiatric practice and 2 to 5 assisted suicides. Excluding those who had ever assisted, 345 of the respondents (64 percent) thought physician-assisted suicide because of a mental disorder could be acceptable, including 241 who said they could conceive of instances in which they themselves would be willing to assist. The most frequent reasons for refusing were the belief that the patient had a treatable mental disorder, opposition to assisted suicide in principle, and doubt that the suffering was unbearable or hopeless. Most, but not all, patients who had been assisted by their psychiatrists in suicide had both a mental disorder and a serious physical illness, often in a terminal phase.

Thirty percent of the respondents had been consulted at least once by a physician in another specialty about a patient's request for assisted death. The annual number of such consultations was estimated at 310, about 3 percent of the estimated 9700 requests for euthanasia or physician-assisted suicide in medical practice.

Conclusions Explicit requests for physician-assisted suicide are not uncommon in psychiatric practice in the Netherlands, but these requests are rarely granted. Psychiatric consultation for medical patients who request physician-assisted death is relatively rare. (N Engl J Med 1997;336:1795-801.)

(c)1997, Massachusetts Medical Society.
I $\mathrm{N}$ the Netherlands, euthanasia and physicianassisted suicide are subject to criminal prosecution, although this rarely occurs. When requested by a competent patient suffering unbearably from an irreversible illness, these practices are accepted by the majority of the general public and the medical profession. ${ }^{1,2}$ In 1994 a court ruled against a psychiatrist who had assisted in the suicide of a 50 -year-old woman who wished to end her life after having lost her two sons. She had mental suffering but was not terminally ill. Dr. Boudewijn Chabot was found guilty of intentionally assisting another person to commit suicide. However, no punishment or other disciplinary measure was imposed. The Dutch Supreme Court stated that although seven independent medical experts had been consulted on all the relevant aspects of the case, at least one consultant should have seen and examined the patient before giving an opinion. The psychiatrist was convicted because of this inadequate consultation. The Supreme Court, however, also judged that unbearable mental suffering can in exceptional cases justify physician-assisted suicide, even if there is no concurrent medical disease, and that the degree of suffering rather than its cause is decisive. ${ }^{3-5}$

Physician-assisted suicide for psychiatric patients is subject to the procedure for reporting physicianassisted death that has been used in the Netherlands since 1991. Our study was part of the evaluation of this procedure, which was commissioned by the ministers of health and justice in $1995^{1,6}$ We sought to obtain reliable estimates of the incidences in psychiatric practice of requests for physician-assisted suicide and of compliance with such requests; to describe the characteristics of the patients, physicians, and circumstances involved; to explore the role of

From the Department of Public Health (J.H.G., P.J.M., A.H.) and the Department of Psychiatry (W.J.S.), Erasmus University, Rotterdam; the Institute for Research in Extramural Medicine, Vrije Universiteit, Amsterdam (G.W.); the Department of Psychiatry, Leiden University, Leiden (M.W.H.); and the Department of Psychiatry, University Hospital, Groningen (A.J.T.) - all in the Netherlands. Address reprint requests to Dr. Groenewoud at the Department of Public Health, Erasmus University, Rotterdam, P.O. Box 1738, 3000 DR Rotterdam, the Netherlands. 
psychiatrists as consultants to other physicians in euthanasia or physician-assisted suicide; and to explore their opinions about review procedures for physician-assisted death in psychiatric practice.

\section{METHODS}

\section{Sample}

Psychiatrists registered before January 1, 1994, were selected from the register of the Royal Dutch Medical Association, which includes all accredited specialists in the Netherlands. Addresses were organized according to postal code, and every second psychiatrist was included in the sample.

\section{Questionnaire}

In March 1996, all 673 psychiatrists in the sample received a 1-page questionnaire eliciting personal data (age, sex, and domain of practice) and a 20-page questionnaire asking whether they had ever received a request for physician-assisted suicide and if so, how often in 1994 and 1995 and whether they had ever acceded to such a request. Detailed information about the most recent case was requested. Respondents were asked whether they had ever been consulted by other physicians about patients' requests for euthanasia or physician-assisted suicide and if so, how often in 1994 and 1995. There were questions about the respondents' attitudes toward physician-assisted death and toward consultation and about their opinions on review procedures. Each questionnaire and a card with the respondent's name and address were to be returned in separate envelopes after the respondent had marked both questionnaires with a code to enable the researchers to combine the information. Thus, complete anonymity could be guaranteed without precluding the sending of reminders to nonrespondents. Data were collected until July 1996.

\section{Response}

Of the 673 psychiatrists selected for the sample, 6 did not meet the criteria for selection and therefore were excluded from the study. Of the remaining 667,552 returned completed questionnaires (a response rate of 83 percent, with 3 responses that could not be used). An additional 6 psychiatrists had chronic illnesses or could not be traced. Fifty-one psychiatrists refused to participate, and for 55 other nonrespondents the reason could not be determined. Of the 104 nonrespondents with available data and the 549 respondents, 82 (79 percent) and 388 ( 71 percent), respectively, were male. Nonrespondents were slightly older, with a mean age of 49.7 years (range, 33 to 67 ), as compared with 47.4 (range, 33 to 77 ) for respondents. Of the nonrespondents, 31 (28 percent) provided written or oral information about a number of core issues in the questionnaire. These 31 did not differ markedly from the respondents with respect to their places of work or experience with requests for physician-assisted suicide and consultation.

\section{Statistical Analysis}

Annual frequencies were estimated by averaging and weighting the numbers of requests for physician-assisted suicide, of actual instances of assistance, and of consultations in 1994 and 1995. The weighting factor was calculated by dividing the number of psychiatrists in the register by the number of respondents.

\section{RESULTS}

\section{Requests for Physician-Assisted Suicide}

Of the 552 respondents, 205 (37 percent) had at least once received an explicit and persistent request for physician-assisted suicide from a patient. Twelve ( 2 percent) had at least once assisted in suicide (Ta- ble 1). Apart from the respondents who had actually assisted in suicide, 345 respondents (64 percent) thought physician-assisted suicide for psychiatric patients could be acceptable; of those, 241 said they could conceive of a situation in which they would be willing to assist in suicide (Table 1 ).

The total incidence of explicit requests for physician-assisted suicide in psychiatric practice was estimated to be about 320 per year. Detailed information was obtained from 202 respondents about their most recent requests: 65 requests were made between 1977 and 1993, and 137 in 1994 or later. Total numbers vary slightly because of missing data.

Of the 201 requests for which there were data on the sex of the patient, 127 (63 percent) were made by female patients. The patients' ages ranged from 16 to 80 years (mean, 44.9 ); 124 of the 194 requests (64 percent) by patients whose ages were known were by patients younger than 50 . The predominant psychiatric diagnosis was a mood disorder (Table 2); 130 of 202 patients (64 percent) had personality disorders. Forty-five patients (22 percent) also had somatic diseases.

At the time of their requests, 114 of the $200 \mathrm{pa}^{-}$ tients on whom such information was available $(57$ percent) were in outpatient treatment; half of this group had been hospitalized before, and of those, 40 percent had been hospitalized involuntarily at least once. The other patients were hospitalized at the time of the request: 63 (32 percent) in psychiatric hospitals, 13 ( 6 percent) in psychiatric wards of general hospitals, and the remaining 10 (5 percent) in other institutions, such as nursing homes.

Of the 202 patients, 129 (64 percent) refused the remaining psychiatric treatment options: medication (63 percent), psychotherapy (63 percent), electroconvulsive therapy (20 percent), and inpatient or day-care treatment ( 16 percent). According to the respondents, the wish to die was persistent in 135 of 194 patients (70 percent), and 172 of 200 (86 percent) requested assistance in suicide without pressure from others. Pressure from others was mentioned by 28 respondents; for 9 of the 12 patients for whom such information was available, the patients' relatives seemed to have an important role in the request. Sixty-four of 200 patients (32 percent) were considered competent (that is, able to assess the situation and make a decision about it adequately). The most frequent reasons for requesting assistance in suicide were the absence of any hope of improvement (68 percent), unbearable mental suffering ( 58 percent), being a burden to others (29 percent), pain or other physical suffering (18 percent), and the loss of dignity (14 percent).

Forty-three of the 202 respondents (21 percent) contemplated granting the patients' requests for physician-assisted suicide. Of those, 40 consulted one or more colleagues each: 30 consulted a psychiatrist 
Table 1. Psychiatrists' Practices and Attitudes with Respect to Physician-Assisted Suicide BeCAuse of a Mental Disorder.

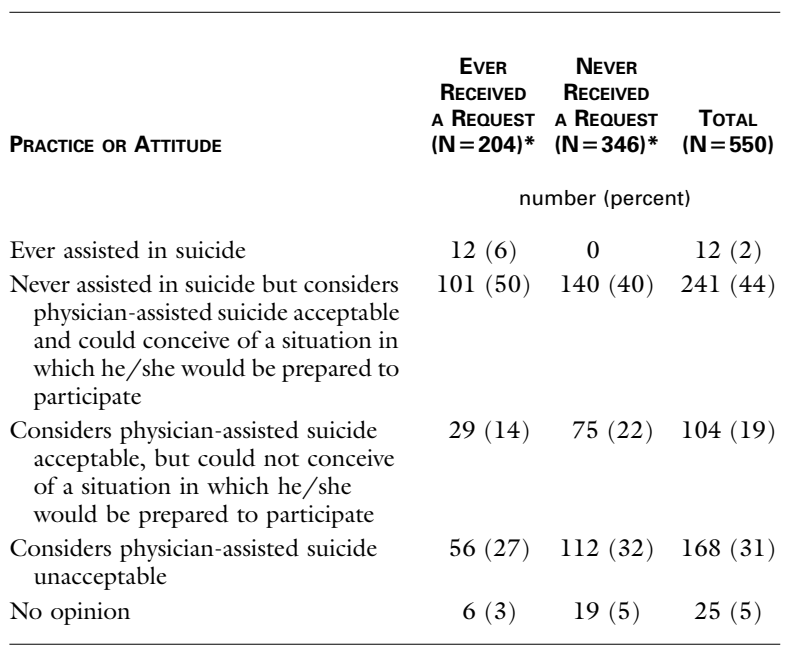

* One respondent in the group did not provide an answer and was therefore excluded from the analysis.

Table 2. Psychiatric Diagnoses in Patients Who Requested PHYSICIAN-Assisted Suicide.

\begin{tabular}{|c|c|c|c|}
\hline DIAGNOSIS & $\begin{array}{l}\text { No Personality } \\
\text { DisORDER } \\
(\mathbf{N}=72)\end{array}$ & $\begin{array}{l}\text { PERSONALITY } \\
\text { DISORDER } \\
(\mathrm{N}=\mathbf{1 3 0})\end{array}$ & $\begin{array}{c}\text { TotaL* } \\
\text { ( } \mathbf{N}=\mathbf{2 0 2})\end{array}$ \\
\hline & \multicolumn{3}{|c|}{ number (percent) } \\
\hline Mood disorder & $40(56)$ & $63(48)$ & $103(51)$ \\
\hline Psychosis & $19(26)$ & $10(8)$ & $29(14)$ \\
\hline Other mental disorder $\dagger$ & $13(18)$ & $11(8)$ & $24(12)$ \\
\hline No mental disorder $\dagger$ & 0 & $46(35)$ & $46(23)$ \\
\hline
\end{tabular}

*Three of 205 respondents did not describe the last time they received a request for physician-assisted suicide and were therefore excluded from the analysis.

†"Other mental disorder" includes, for example, dissociative and panic disorders. Personality disorders were excluded from the category.

working in the same institution, 12 consulted a psychiatrist working in another institution, 16 consulted a general practitioner, and 5 consulted another medical specialist. The main reasons for consultation were to assess whether the phenomena of transference and countertransference (the patient's unconscious feelings and attitudes toward the therapist and vice versa) might have influenced the decisionmaking process $(50$ percent), whether the request was well considered (58 percent), and whether there were still treatment options ( 58 percent).

Four of the 202 most recent requests ( 2 percent) resulted in suicides assisted by the responding psy-
Table 3. Psychiatrists' Reasons for Not Granting Requests FOR Physician-Assisted Suicide.*

\begin{tabular}{|c|c|c|c|}
\hline REASON & $\begin{array}{l}\text { DID Not } \\
\text { ConsIDER } \\
\text { GRANTING } \\
\text { THE REQUEST } \\
\text { (N= 159) }\end{array}$ & $\begin{array}{c}\text { Considered } \\
\text { GRANTING } \\
\text { THE REQUEST } \\
(\mathbf{N}=\mathbf{3 8}) \dagger\end{array}$ & $\begin{array}{l}\text { TOTAL } \\
(\mathrm{N}=197) \ddagger\end{array}$ \\
\hline & \multicolumn{3}{|c|}{ number (percent) } \\
\hline Mental disorder could be treated & $107(67)$ & $14(37)$ & $121(61)$ \\
\hline Psychiatrist opposed in principle & $59(37)$ & $3(8)$ & $62(31)$ \\
\hline $\begin{array}{l}\text { Suffering was not unbearable or } \\
\text { hopeless }\end{array}$ & $56(35)$ & $8(21)$ & $64(32)$ \\
\hline Wish to die was not long-standing & $40(25)$ & $5(13)$ & $45(23)$ \\
\hline Request was not well considered & $40(25)$ & $5(13)$ & $45(23)$ \\
\hline Consultant advised against it & - & $10(26)$ & $10(5)$ \\
\hline Respondent had not yet decided & - & $5(13)$ & $5(3)$ \\
\hline Patient no longer wished to die & - & $3(8)$ & $3(2)$ \\
\hline Other reasons $\$$ & $27(17)$ & $4(11)$ & $31(16)$ \\
\hline
\end{tabular}

${ }^{*}$ More than one answer was possible.

†Data were missing on one respondent who considered acceding to the request; this respondent was excluded from the analysis.

$\ddagger$ In an additional four cases, the psychiatrist assisted in the patient's suicide.

\$Other reasons included the presence of a treatable physical disorder, the young age of the patient, or the admission of the patient to another hospital.

chiatrists. In each of six other cases ( 3 percent), another physician assisted in the suicide; two were general practitioners (information about the specialties of the other four was not available). In 10 cases ( 5 percent) the patients died of natural causes, and in 32 cases ( 16 percent) the patients ended their lives without assistance from a physician. One hundred twenty-eight patients (63 percent) were still living: 70 ( 35 percent) no longer wished to end their lives, 37 ( 18 percent) still persistently asked for assistance in suicide, and in 21 ( 10 percent) the requests were less persistent. For 22 patients (11 percent), the respondents had no follow-up information.

The reasons psychiatrists gave for not assisting in suicide are shown in Table 3 . The most frequent were the belief that the patient had a treatable mental disorder, opposition in principle to assisting in suicide, and doubt that the patient's suffering was unbearable or hopeless.

\section{Psychiatrists' Assistance in Suicide}

Respondents who had assisted in suicide were asked how often they had done so in 1994 and 1995 and to describe the most recent case. On the basis of the answers to the first question, physician-assisted suicide in psychiatric practice was estimated to occur two to five times per year in the Netherlands; none of the respondents reported having assisted in 
Table 4. Description of 11 Patients Whose Psychiatrists Helped Them Commit Suicide.

\begin{tabular}{|c|c|c|c|c|c|c|}
\hline \multirow[t]{3}{*}{$\begin{array}{l}\text { Patient } \\
\text { No. }\end{array}$} & \multirow[t]{3}{*}{$\begin{array}{c}\text { SeX/ } \\
\text { AgE (YR) }\end{array}$} & \multicolumn{2}{|c|}{ Diagnosis* } & \multicolumn{2}{|c|}{ PSYCHIATRIC HISTORY } & $\begin{array}{l}\text { Psychiatrist's Main ReAsons } \\
\text { FOR Assisting }\end{array}$ \\
\hline & & & & & $\begin{array}{l}\text { PREVIOUS } \\
\text { INPATIENT }\end{array}$ & \\
\hline & & PSYCHIATRIC & MEDICAL & DURATION & TREATMENT & \\
\hline 1 & $\mathrm{~F} / 28$ & $\begin{array}{l}\text { Mood disorder, personality } \\
\text { disorder }\end{array}$ & None & $\sim 3 \mathrm{yr}$ & Yes & Unknown \\
\hline 2 & $\mathrm{~F} / 40$ & Personality disorder & Whiplash, post-traumatic epilepsy & $6 \mathrm{mo}$ & No & Failure of all treatment \\
\hline 3 & $\mathrm{M} / 60$ & $\begin{array}{l}\text { Mood disorder, personality } \\
\text { disorder }\end{array}$ & Severe respiratory disease & $\sim 7 \mathrm{yr}$ & Yes & $\begin{array}{l}\text { Unbearable or hopeless mental suffering, } \\
\text { prevention of violent suicide }\end{array}$ \\
\hline 4 & $\mathrm{M} /$ Unknown & $\begin{array}{l}\text { Mood disorder, personality } \\
\text { disorder }\end{array}$ & $\begin{array}{l}\text { Respiratory disease, terminal } \\
\text { phase }\end{array}$ & $3 \mathrm{mo}$ & Yes & Unbearable or hopeless physical suffering \\
\hline 5 & $\mathrm{~F} / 57$ & $\begin{array}{l}\text { Somatization disorder, } \\
\text { personality disorder }\end{array}$ & Suspected neurologic disease & $3 \mathrm{yr}$ & Yes & $\begin{array}{l}\text { Unbearable or hopeless physical suffering, } \\
\text { failure of all treatment, prevention of } \\
\text { violent suicide }\end{array}$ \\
\hline 6 & $\mathrm{~F} / 47$ & Mood disorder & Terminal cancer & $\sim 12 \mathrm{mo}$ & No & $\begin{array}{l}\text { Unbearable or hopeless physical suffering, } \\
\text { failure of all treatment, prevention of } \\
\text { further physical and psychological } \\
\text { deterioration }\end{array}$ \\
\hline 7 & $M / 34$ & Organic mental disorder & AIDS & $4 \mathrm{mo}$ & No & $\begin{array}{l}\text { Unbearable or hopeless physical suffering, } \\
\text { failure of all treatment }\end{array}$ \\
\hline 8 & $\mathrm{~F} / 32$ & Psychosis & Terminal renal disease & $12 \mathrm{yr}$ & Yes & Unbearable or hopeless physical suffering \\
\hline 9 & $\mathrm{~F} / 38$ & Mood disorder & Terminal cancer & Unknown & Yes & $\begin{array}{l}\text { Unbearable or hopeless physical suffering, } \\
\text { unbearable or hopeless mental suffer- } \\
\text { ing, failure of all treatment }\end{array}$ \\
\hline 10 & $\mathrm{M} / 41$ & None & AIDS & $3 \mathrm{mo}$ & No & Unbearable or hopeless physical suffering \\
\hline 11 & $\mathrm{M} / \sim 80$ & None & Neurologic disease, terminal phase & Unknown & No & Failure of all treatment \\
\hline
\end{tabular}

*AIDS denotes acquired immunodeficiency syndrome.

suicide more than once during 1994 and 1995. Eleven cases were described (Table 4). Most of these patients each had both a mental disorder and a serious physical illness. The most frequently mentioned reasons for assisting in suicide were that the patient's physical suffering was unbearable or hopeless and that all previous treatment had failed.

One psychiatrist assisted a patient by helping him prepare for the suicide; the medication was prescribed by a general practitioner. Eight patients died after taking medication prescribed by respondents; in two other cases (both involving a serious physical disease), psychiatrists administered the drugs. Six patients died at home, two in psychiatric wards, two in medical wards, and one elsewhere. Seven respondents had been present at the suicides. Three respondents had reported the suicides as unnatural deaths. The most important reasons for not reporting a suicide were fear of prosecution (mentioned by four respondents); the belief that it was a private matter between doctor and patient, the wish to protect the patient's relatives from judicial inquiry, a request by relatives to be protected from judicial inquiry (each mentioned twice); the patient's wish, not having fulfilled the requirements necessary to avoid prosecution, ${ }^{6}$ advice from a colleague, a previous unfavorable experience with reporting a death as an unnatural death, and the wish to protect the re- spondent's relatives from judicial inquiry (each mentioned once). In another case - that of a woman in her 40s who had had a mood disorder for many years but had no somatic disorder - the psychiatrist helped her prepare for the suicide but the patient finally decided against it.

\section{Psychiatrists' Role in Consultation}

Of 549 respondents, 164 (30 percent) had been asked at least once for consultation by a physician from another specialty about a patient's request for euthanasia or physician-assisted suicide. The annual number of such consultations was estimated to be about $310 ; 161$ of the most recent cases were described (Table 5). Of 161 physicians who asked for psychiatric consultation, 80 (50 percent) were general practitioners, 60 (37 percent) were clinical specialists, 10 (6 percent) were nursing home physicians, and 10 ( 6 percent) were other medical professionals. The specialty of one physician was unknown. In 112 of 161 consultations (70 percent) the purpose was to assess whether a treatable mental disorder was present, in 111 cases (69 percent) it was to assess whether the patient's request was well considered, and in 29 cases (18 percent) it was to determine whether transference or counter-transference was influencing the decision-making process. Fifteen of 161 respondents (9 percent) did not ex- 
Table 5. Psychiatric Consultations about Physician-Assisted Death.

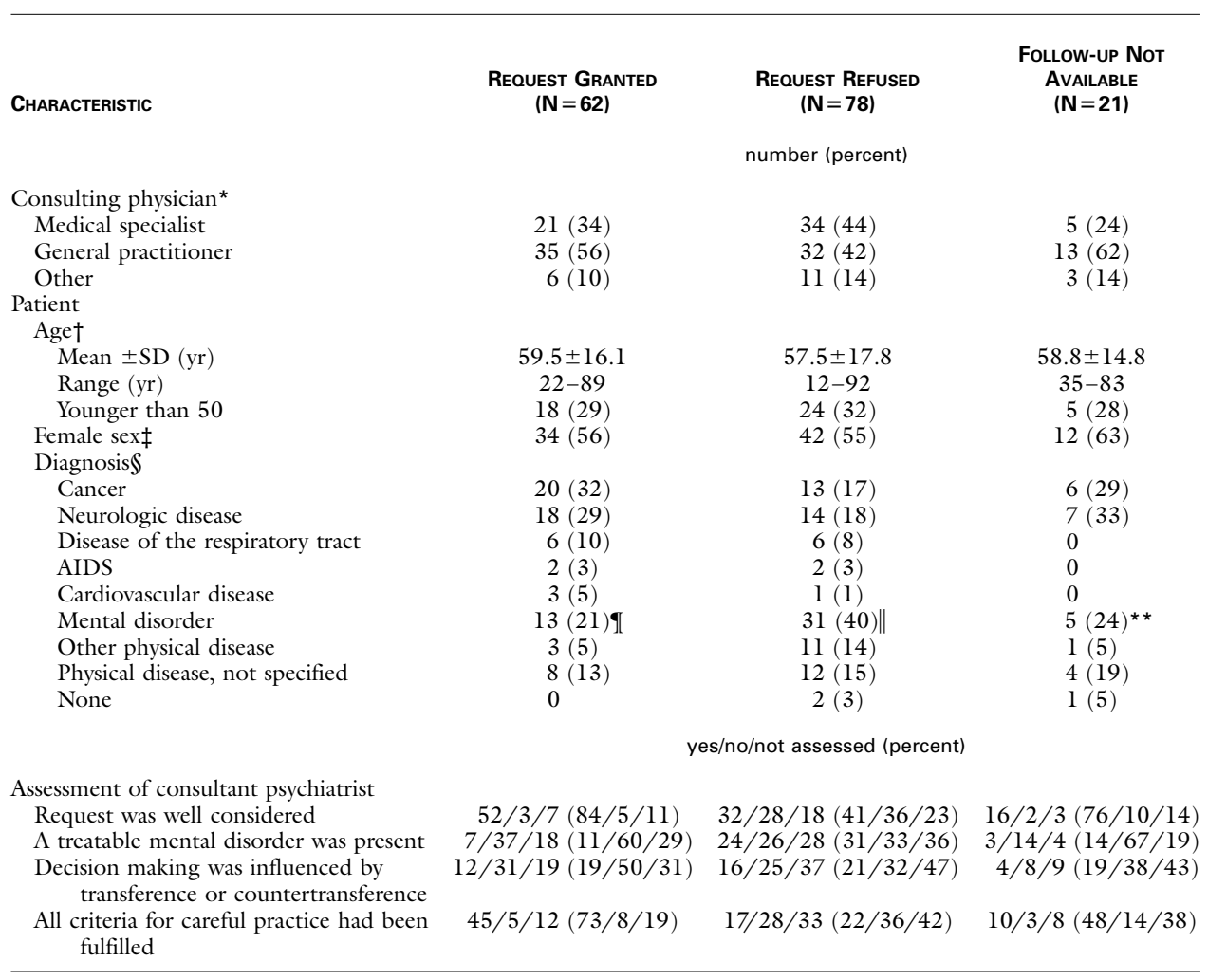

*Data were missing for one case in the second group.

†Data were missing for three cases in the second group and three cases in the third group.

$\ddagger$ Data were missing for one case in the first and second groups and for two cases in the third group.

\$Percentages do not add up to 100 percent because in some cases more than one principal diagnosis was mentioned by the respondent.

ISeven of the 13 patients also had a somatic disorder; 2 of them requested physician-assisted suicide because of the mental disorder, 4 because of both the mental and the physical disorder, and 1 for another reason.

\|Eleven of the 31 patients also had a physical disorder; these patients' reasons for requesting physician-assisted suicide were the physical disorder in 3 , both the mental and the physical disorder in 6 , and another reason in 2 .

**Three of the five patients also had a physical disorder; all three patients requested physician-assisted suicide because of the combination of the mental and the physical disorder.

amine the patients themselves; of the 146 (91 percent) who did, 80 did so more than once. In 62 of 161 cases (39 percent), the patients' requests resulted in physician-assisted death, in 78 (48 percent) it did not, and in 21 (13 percent) the respondents had no follow-up information. The patients whose requests were finally granted were similar in age and sex to the patients whose requests were not (Table 5 ). Patients whose requests were granted more frequently had cancer or neurologic disease, whereas patients whose requests were not granted more frequently had mental disorders. According to the respondents, among the patients whose requests were granted the request was more often well considered, a treatable mental disorder was more often absent, and the criteria for careful practice were more frequently fulfilled.

\section{Opinions about Requirements for Careful Practice and Consultation}

Psychiatrists who thought physician-assisted suicide was acceptable for psychiatric patients were asked about the importance they attached to several official and unofficial requirements for careful decision making. A well-considered request was thought to be important or very important by 346 of 355 respondents (97 percent). Other important considerations were that the requests be voluntary (considered important or very important by 336 of 354 , or 95 percent), that there be no hope of improvement (319 of 350 , or 91 percent), that treatment alternatives be expected to have no or very little effect (321 of 352 , or 91 percent), that mental suffering be unbearable (316 of 354 , or 89 percent), and that the request be written (182 of 349 , or 52 percent). 
The respondents who had ever assisted in suicide and those who could conceive of a situation in which they would be prepared to do so were asked how important they considered a number of other aspects of the decision-making process. The characteristics of the disease were considered to be important or very important by 196 of 216 respondents (91 percent); the duration and character of previous treatment, by 192 of 217 ( 88 percent); the duration and burden of treatment alternatives, by 133 of 216 (62 percent); the opinion of relatives, by 79 of 217 (36 percent); the age of the patient, by 65 of 216 (30 percent); and the threat of a violent suicide, by 71 of 215 (33 percent).

According to 509 of 532 respondents (96 percent), one or more psychiatrists should be consulted when physician-assisted suicide because of mental suffering is considered by a physician. When euthanasia or physician-assisted suicide because of physical suffering is considered, 101 of 544 respondents (19 percent) said psychiatric consultations should always be requested; 422 (78 percent) thought a psychiatrist should be consulted only if the attending physician judged it necessary. Of 537 respondents, 438 (82 percent) thought that the psychiatric consultant should always examine the patient. Ninetythree (17 percent) thought this was necessary in some but not all cases, and 6 ( 1 percent) thought it unnecessary.

\section{DISCUSSION}

We believe that the information we collected presents a reliable overview of end-of-life decision making in Dutch psychiatric practice. The sample of psychiatrists was large and the response rate was 83 percent, the questionnaires were filled out carefully, absolute anonymity was guaranteed, and the data could not be used for criminal prosecution.

Explicit and persistent requests for physicianassisted suicide are not uncommon in Dutch psychiatric practice. The annual number of such requests was estimated to be about 320 . In the Netherlands (population, about 15 million), the total number of patients receiving mental health care is about 400,000 , and the number of psychiatric patients in institutions is about 26,000. In all Dutch medical practice (not just psychiatric), the annual number of explicit requests for euthanasia and physician-assisted suicide was estimated to be 9700 , of which 3600 (37 percent) were acceded to. ${ }^{1}$ In psychiatric practice, however, only about 2 percent of the requests were finally granted. The estimated annual number of suicides in which a psychiatrist assisted was two to five. At least half of these involved a psychiatric patient who also had a serious physical disease, often in a terminal phase. Thus, although nearly two thirds of the Dutch psychiatrists who responded to the survey considered assisted suicide for psychiatric pa- tients acceptable, and a majority of them could conceive of a situation in which they would be prepared to assist, physician-assisted suicide in Dutch psychiatric practice is extremely rare.

Psychiatric patients requesting physician-assisted suicide were relatively young: 64 percent were under 50 , as compared with 16 percent of all patients requesting euthanasia or physician-assisted suicide.

In its verdict in the Chabot case in 1994, the Dutch Supreme Court stated that (1) the absence of a medical illness means that extreme care should be applied in assessing the seriousness of suffering and the prospect for successful treatment; (2) if the patient deliberately refuses a realistic alternative to alleviate suffering, assistance in suicide is not justified; and (3) an independent expert must be consulted on all the relevant aspects of the case and must have examined the patient before giving an opinion. ${ }^{3-5}$ These statements were in line with earlier positions of the Royal Dutch Medical Association ${ }^{7}$ and are reflected in our findings. About two thirds of the patients whose requests for physician-assisted suicide were refused were not considered fully competent by the respondents. The most frequently mentioned reasons for refusing a request were the presence of a treatable mental disorder and the advice of a consultant physician (especially in cases in which the respondent contemplated acceding to the request).

Although the Dutch Supreme Court did not state whether the expert who is consulted has to be a psychiatrist, nearly all the respondents stated that one or more psychiatrists should be consulted when physician-assisted suicide is considered for a psychiatric patient. Only 19 percent thought that consultation with at least one psychiatrist should be mandatory when euthanasia or physician-assisted suicide is considered because of somatic suffering. Most respondents thought that the attending physician should decide whether such consultation is necessary. This is in line with medical and legal practices in the Netherlands and with the results of a survey among members of the Netherlands Consortium of Consultation-Liaison Psychiatry. ${ }^{8}$ The majority in that survey preferred that the consultation be initiated by the primary care giver and rejected mandatory consultation by a psychiatrist in each case.

Baile et al. argued that comprehensive psychosocial assessment is needed when any request for assistance in dying is evaluated. ${ }^{9}$ Block and Billings stated that most patients, in saying they want to die, are actually asking for assistance in living and delineated the role of psychiatrists in evaluating and managing such requests. ${ }^{10}$ Some studies on the psychiatric aspects of terminal somatic illness support this view. Chochinov et al. found that diagnosed depression syndromes were present in 10 of 17 terminally ill patients with a wish to die. ${ }^{11}$ Emanuel et al. ${ }^{12}$ found that patients with cancer who had depression and 
psychological distress were significantly more likely to have seriously discussed euthanasia, hoarded drugs, or read Derek Humphry's Final Exit. ${ }^{13}$ In our study, we found that 30 percent of the respondents had ever been consulted by a nonpsychiatrist colleague; the annual number of psychiatric consultations requested by nonpsychiatrists because patients had requested euthanasia or physician-assisted suicide was about 310 . This represents about 3 percent of the annual number of explicit requests for euthanasia and physician-assisted suicide in the Netherlands. This finding does not imply that psychiatric and psychosocial aspects were neglected in the other patients. Van der Wal and van der Maas found that in 31 percent of requests refused by the physician, the reason was that the patient had depression or another mental disorder, whereas in all instances of euthanasia and physician-assisted suicide the patient was judged to be fully competent. ${ }^{14}$ Obviously, the possibility that depression was overlooked or not identified in some patients cannot be excluded.

In Dutch psychiatry, there is a rather liberal attitude toward physician-assisted suicide in psychiatric patients but a very reluctant practice. Consultation of a psychiatrist about requests for euthanasia or physician-assisted suicide because of medical diseases is relatively rare and perhaps should occur more often, although most Dutch psychiatrists think that the primary care giver should decide whether psychiatric consultation is necessary.

Supported by grants from the Dutch Ministry of Health, Welfare, and Sports and the Ministry of Justice.
We are indebted to E.S. Goes, M.Sc., and E.M.H.H. Wolfs for their help during the study and to all the psychiatrists who completed the questionnaire.

\section{REFERENCES}

1. van der Maas PJ, van der Wal G, Haverkate I, et al. Euthanasia, physician-assisted suicide, and other medical practices involving the end of life in the Netherlands, 1990-1995. N Engl J Med 1996;335:1699-705.

2. van der Maas PJ, Pijnenborg L, van Delden JJM. Changes in Dutch opinions on active euthanasia, 1966 through 1991. JAMA 1995;273:14114.

3. Griffiths J. Assisted suicide in the Netherlands: the Chabot case. Modern Law Rev 1995;58:232-48.

4. Gevers S. Physician assisted suicide: new developments in the Netherlands. Bioethics 1995;9:309-12.

5. Hoge Raad, 21 juni 1994. Hulp bij zelfdoding psychiatrische patiënt. Ned Jurisprudentie 1994;656:3142.

6. van der Wal G, van der Maas PJ, Bosma JM, et al. Evaluation of the notification procedure for physician-assisted death in the Netherlands. N Engl J Med 1996;335:1706-11.

7. Commissie Aanvaardbaarheid Levensbeëindigend Handelen. Discussienota: hulp bij zelfdoding bij psychiatrische patiënten. Utrecht, the Netherlands: Koninklijke Nederlandsche Maatschappij tot bevordering der Geneeskunst, 1993.

8. Huyse FJ, van Tilburg W. Euthanasia policy in the Netherlands: the role of consultation-liaison psychiatrists. Hosp Community Psychiatry 1993;44 733-8.

9. Baile WF, DiMaggio JR, Schapira DV, Janofsky JS. The request for assistance in dying: the need for psychiatric consultation. Cancer 1993;72: 2786-91.

10. Block SD, Billings JA. Patient requests for euthanasia and assisted suicide in terminal illness: the role of the psychiatrist. Psychosomatics 1995; 36:445-57.

11. Chochinov HMC, Wilson KG, Enns M, et al. Desire for death in the terminally ill. Am J Psychiatry 1995;152:1185-91.

12. Emanuel EJ, Fairclough DL, Daniels ER, Clarridge BR. Euthanasia and physician-assisted suicide: attitudes and experiences of oncology patients, oncologists, and the public. Lancet 1996;347:1805-10.

13. Humphry D. Final exit: the practicalities of self-deliverance and assisted suicide for the dying. Eugene, Oreg.: Hemlock Society, 1991.

14. van der Wal G, van der Maas PJ. Euthanasie en andere medische beslissingen rond het levenseinde: de praktijk en de meldingsprocedure. Den Haag, the Netherlands: Sdu Uitgevers, 1996 